Theological College of Northern Nigeria (TCNN) Research Bulletin

Dr Gunther J. Hermann, Chairman of the Editorial Board, writes:

For almost two years now TCNN has been publishing a research magazine called TCNN Research Bulletin. Up to now five issues (each of about forty pages) have been published (two-three issues per year). The aim of the Bulletin is to encourage research in Northern Nigeria related to questions of African traditional religion, Islam, Nigerian church history, mission and colonialism, modernization and problems of a social, ethical, political or philosophical nature.

The first editorial principle is that all articles must have a clear relevance to the African or especially Nigerian context. Only present and former students of TCNN, as well as present and former staff members of the college, are eligible to contribute to the Bulletin. The second editorial principle is to avoid theological jargon. The Bulletin does not aim at being a forum for international scholars, but it is intended to be read and understood by a wider public.

Although the Bulletin is not primarily intended for a readership outside West Africa, it has a role in supplementing existing research at the international, academic level by serving as an outlet for the original, local research done by students and graduates of TCNN. Recent issues have included papers on:

Marriage customs among the Tiv

The Bura myth and Christian parallels

Death and burial among the Fali people

Knowing and evangelizing the Verre people

The relationship between mission and colonialism in northern Nigeria

The TCNN Research Bulletin is produced at TCNN on a duplicating machine and distributed as much as possible by handmail to keep subscription costs down. The price for four issues of the Bulletin is $\$ 2.40$ (postage included), and arrangements can be made for payment in dollars, pounds Sterling, or DM through bookshops in the USA, UK and West Germany. For further details contact:

Rev. Gunther J. Hermann,

Theological College of Northern Nigeria,

P.O. Box 64,

Bukuru,

Plateau State,

Nigeria.

\title{
Aman: Fournal of Society Culture and Environment
}

We have received a copy of the first issue of this new journal published by the Centre for Social, Cultural and Environmental Research at the University of Benin. One hundred and twenty pages long, it contains eight papers ranging from studies of the legal significance of women-to-women marriage and the social cost of illegal abortion in Nigeria, through three papers on educational topics to two studies of urban environmental problems. The Editor-in-Chief, Professor F. I. A. Omu, contributes a paper on the world information system in relation to Nigeria. 
Aman is published twice a year, and the annual subscription is $\mathbb{6} 6.00$. Enquiries and subscriptions to:

\author{
The Editor-in-Chief, \\ Aman, \\ Centre for Social, Cultural and \\ Environmental Research, \\ University of Benin, \\ P.M.B. 1154, \\ Benin City, \\ Bendel State, \\ Nigeria.
}

\title{
Africana Directions
}

The Information Office of the Library of Congress, Washington D.C., announces Africana Directions, a new series of guides prepared by the African Section of the Library of Congress. To be issued irregularly, they will consist of brief bibliographies, reading lists or reference aids on topics of current interest. Africana Directions will not only be of value to visitors to the Library's African Section, but will also serve the needs of other scholars and librarians interested in the dynamic political, economic, or social environment of sub-Saharan Africa.

The first issue in the new series, an especially topical bibliography, is a fourteen-page list of references entitled Recent Afro-Libyan Relations compiled by Joanne $M$. Zellers. It includes one hundred and five entries and a map. Future issues in the series will generally not exceed ten pages in length. Titles in the series will be numbered sequentially by year. Recent Afro-Libyan Relations is AD 81-1.

This issue of Africana Directions concerns Afro-Libyan relations since 1976 and West African reactions to Libyan involvement in Chad. Compiled from Western language sources, the list is divided into three main sections: recent sources on Afro-Arab relations; general Afro-Libyan relations since 1976; and Libyan relations with selected African countries. Catalogued works are identified by call numbers and uncatalogued material by the symbol DLC. A map of Africa is included for reference.

Copies of Recent Afro-Libyan Relations and future issues in this series are available free of charge from:

The Library of Congress,

African and Middle Eastern Division,

African Section,

Washington, D.C. 20540.

The Britain-Zimbabwe Society

Friendship societies between Britain and other countries are legion; the Britain-Zimbabwe Society, inaugurated at a public meeting at the Africa Centre, Covent Garden, on 29 October 1981, is unusual in that most of its initial membership was drawn not from retired diplomats or ex-colonial officers but from the ranks of those people who consistently advocated the principle of 'No independence before 